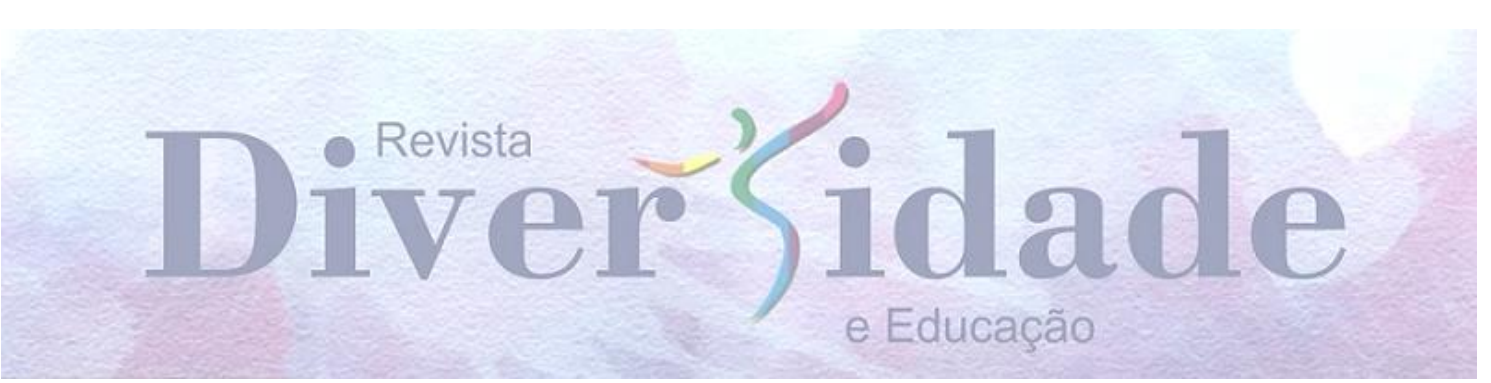

\title{
GÊNERO E SEXUALIDADE NA BNCC: UMA ANÁLISE SOB A PERSPECTIVA FREIREANA
}

\author{
GÉNERO Y SEXUALIDAD EN BNCC: UN ANÁLISIS EN EL \\ PERSPECTIVA FREIREANA
}

\section{GENDER AND SEXUALITY AT BNCC: AN ANALYSIS UNDER THE FREIREAN PERSPECTIVE}

\author{
Juliana Collares da Silva ${ }^{1}$
}

André de Azambuja Maraschin ${ }^{2}$

Catiúcia Anselmo Funari ${ }^{3}$

Elena Maria Billig Mello ${ }^{4}$

Sônia Maria da Silva Junqueira ${ }^{5}$

\section{RESUMO}

O presente artigo discute a diversidade sexual e de gênero na BNCC, a partir de olhares e perspectivas freireanas, na intenção de conhecer de que forma a Base aborda estas temáticas no documento final, publicado em 2018. Para tanto, discorremos sobre os entrelaçamentos de gênero e sexualidade com a área educacional, tecendo aproximações em torno do currículo e cultura nas obras de Paulo Freire. Para este estudo, em relação aos procedimentos metodológicos, nos assentamos na análise documental, adotando uma abordagem qualitativa. Ao considerar as reflexões obtidas a partir desta análise, é possível afirmar que a $\mathrm{BNCC}$ retrocede no que se refere às questões relacionadas a essas temáticas.

PALAVRAS-CHAVE: BNCC. Gênero. Sexualidade. Paulo Freire.

\section{RESUMEN}

En este artículo se discute la diversidad sexual y de género en BNCC, desde las miradas y perspectivas freireanas, con la intención de conocer cómo la Base aborda estos temas en el documento final, publicado en 2018. Para ello, nosotros hablamos sobre los entrelazamientos de género y sexualidad con el área educacional, tejiendo

\footnotetext{
${ }^{1}$ Mestranda do Programa de Pós-graduação Mestrado Acadêmico em Ensino e membro do Grupo de Estudos em Educação, História e Narrativas (GEEHN), na Universidade Federal do Pampa- Campus Bagé/RS.

${ }^{2}$ Licenciado em Química.

${ }^{3}$ Licenciada em Química.

${ }^{4}$ Doutora em Educação.

${ }^{5}$ Doutora em Educação Matemática.
} 
aproximaciones en torno al currículo y la cultura en las obras de Paulo Freire. Para este estudio, en relación a los procedimientos metodológicos, nos basamos en el análisis documental, adoptando un enfoque cualitativo. Cuando se considera las reflexiones obtenidas de este análisis, es posible afirmar que el BNCC retrocede sobre las cuestiones relacionadas con estos temas.

PALABRAS-CLAVE: BNCC. Género. Sexualidad. Paulo Freire.

\section{ABSTRACT}

This article is about a discussion involving sexual and gender diversity on BNCC from Freire's point of view and perspectives with the intention of knowing how the Base comprises these topics in the final document published in 2018. For that, we discuss the involvement of gender and sexuality with the educational area, weaving approaches around the curriculum and culture in the works of Paulo Freire. Thus, regarding the methodological procedures, this study is based on a documental analysis, adopting a qualitative approach. When considering the results obtained from this analysis it is possible to assure that the document $\mathrm{BNCC}$ retreats regarding the issues related to these topics.

KEYWORDS: BNCC. Gender. Sexuality. Paulo Freire.

$$
* * *
$$

Gosto de ser gente porque, inacabado, sei que sou um ser condicionado, mas, consciente do inacabamento, sei que posso ir mais além dele. Esta é a diferença profunda entre o ser condicionado e o ser determinado.

Paulo Freire

\section{Introdução}

A escrita deste artigo nasce da proposta de um componente curricular do curso de Mestrado Acadêmico em Ensino, da Universidade Federal do Pampa campus Bagé, denominada Currículo, interdisciplinaridade no ensino. Com o transcorrer das aulas, que se dedicaram à leitura e análise atentas da Base Nacional Comum Curricular (BNCC), as professoras desafiaram educandos e educandas a elaborarem lives sobre essa temática, se entrelaçando com questões voltadas ao currículo e à interdisciplinaridade. Um dos temas propostos para essa atividade foi a educação crítico e emancipadora, escolhido por nós.

No momento de discutir com o grupo de trabalho que elaboraria essa live, decidimos buscar a BNCC e tecer nossas considerações sobre as temáticas de gênero e sexualidade, temáticas estas que entendemos como urgentes e de extrema relevância social, tendo em vista que o Brasil é um dos países que mais agride e mata sujeitos LGBTQIA+ (Lésbicas, Gays, Bissexuais, Transexuais ou Transgêneros, Queer, 
Intersexo, Assexual) e vem demonstrando nos últimos anos, muita dificuldade em estabelecer estes debates no contexto escolar, principalmente por interferências dos vieses políticos e religiosos a que alguns grupos insistem em aplicar culminando em mudanças nos documentos norteadores da educação brasileira, o que nos alerta para o poder de persuasão que exercem sobre a sociedade.

Portanto, para dar início ao presente estudo da BNCC, elaboramos a seguinte questão: "de que forma as temáticas de gênero e sexualidade transitam pelo texto final da BNCC?". Com o objetivo de responder a esta indagação, situamos nossa escrita como resultado de uma análise documental, que "seleciona, trata e interpreta a informação" (KRIPKA; SCHELLER; BONOTTO, 2015, p. 243) contida neste documento oficial, apresentando tratamento analítico a esta fonte que podemos considerar recente, e que portanto requer maior exploração por parte da comunidade acadêmica. A análise ora feita buscou refletir se, na perspectiva crítico-emancipadora, as temáticas de gênero e sexualidade se mostram viáveis, ou seja, se a BNCC permite diferentes abordagens, tais como biológica, cultural, histórica, dentre outras, assim como outros documentos oficiais por exemplo os Parâmetros Curriculares Nacionais $(\mathrm{PCN})^{6}$ e as Orientações Curriculares para o Ensino Médio (OCEM) ${ }^{7}$.

Para tanto, com base no que nos ensina Pimentel (2001), para chegarmos à análise de um documento, é necessário antes que se faça uma "garimpagem", para que consigamos organizar o material produzido e, desta forma, permitir as interpretações em relação a um determinado fenômeno que se apresente no documento a partir de um determinado contexto. Em relação a isso, Cellard (2012, p. 304) também afirma que:

o pesquisador desconstrói, tritura seu material à vontade; depois procede uma reconstrução, com vista a responder ao seu questionamento. Para chegar a isso, ele deve se empenhar em descobrir as ligações entre os fatos acumulados, entre os elementos de informação [...] É esse encadeamento de ligações entre a problemática do pesquisador e as diversas observações extraídas de sua documentação, o que lhe possibilita formular explicações plausíveis, produzir uma interpretação coerente, e realizar uma reconstrução de um aspecto qualquer de uma dada sociedade, neste ou naquele momento.

\footnotetext{
${ }^{6}$ Parâmetros Curriculares Nacionais, que segundo Galian (2014) foi um documento da década de 1990, que atuou no sentido de uniformizar o currículo nacional da educação básica.

${ }^{7}$ Orientações Curriculares para o Ensino Médio, que segundo Ribas, Santos e Sturza (2017) foram elaboradas durante o Governo Lula, a partir da revisão dos PCN, pela Secretaria de Educação Básica (SEB), criada também neste Governo, na intenção de estimular a democratização do acesso, permanência e conhecimento escolar.
} 
Desta forma, buscamos dialogar a partir das ideias e conceitos em torno do gênero e sexualidade, na perspectiva freireana, bem como a aproximação entre currículo e cultura, apresentando nossas reflexões acerca das temáticas na BNCC a partir dessa reconstrução documental.

\section{Gênero e sexualidade: entrelaçamentos na área educacional}

As discussões acerca da temática de gênero - e aqui queremos frisar nosso entendimento relacionado às construções sociais para as feminilidades e masculinidades - constituem há algum tempo a nossa sociedade. As próprias reivindicações de direitos às mulheres datam do período das Revoluções Burguesas, em que mulheres vinculavam a não educação feminina como um dos maiores obstáculos às suas liberdades, que favoreciam a situação de inferioridade a que eram submetidas, denunciando então estas questões em seus escritos. Dentre elas, destacamos as contribuições de Olympe De Gouges, Mary Wollstonecraft e Nísia Floresta, esta última da médica psiquiatra brasileira (PRÁ; CEGATTI, 2016).

Mais recentemente, após a promulgação da Constituição Federal de 1988 no Brasil, alguns segmentos historicamente marginalizados tornam-se mais visíveis, se organizam em movimentos reivindicatórios e conquistam espaço nos discursos políticos e nas políticas públicas. Dentre eles os próprios movimentos de sujeitos LGBTQIA+, os processos de exclusão e violências de que são vítimas, assim como as necessidades de se introduzir nas escolas uma Educação Sexual com vistas à compreensão das diferentes formas de viver e expressar as sexualidades, ganham força também neste cenário.

As discussões no Brasil sobre as temáticas da Educação Sexual foram acentuadas após o período de redemocratização que se seguiu ao fim da ditadura iniciada em 1964 e intensificada com o AI-5, em 1968. A partir da Constituição de 1988 questões de cidadania e direitos passaram a fazer parte dos discursos sociais e políticos, e em seu bojo os marcadores de Gênero e Sexualidade ocuparam lugar de destaque (MONTEIRO; RIBEIRO, 2020, p. 2).

Mesmo assim, é no ano de 2003, no governo do então presidente Luiz Inácio Lula da Silva, que o governo federal vai criar uma Secretaria Especial de Direitos Humanos, e na Educação, conforme nos afirma Souza Júnior (2018, p. 12), "a Secretaria de Educação Continuada, Alfabetização e Diversidade (SECAD), a qual passou a ser chamada de Secretaria de Educação Continuada, Alfabetização, Diversidade e Inclusão 
(SECADI)", que iniciam o desenho de políticas públicas para enfrentamento às desigualdades e violências, unindo academia e outros atores sociais, vinculados à ONG (Organizações Não Governamentais), por exemplo, para executar projetos nos municípios, porque até então, o que existiam eram ações governamentais voltadas à questão da saúde, priorizando a prevenção de doenças como a $\mathrm{AIDS} / \mathrm{HIV}^{8}$, reflexos dos anos 1980. Além do surgimento da epidemia de doenças, César (2009) coloca a gravidez na adolescência como outro fator que desencadeou o caráter de prevenção no que diz respeito à sexualidade, pois ela acontecia em jovens em idade escolar e passou a ser entendida também como um problema pedagógico.

Neste sentido, a escola passa a ganhar força e torna-se visada pelos pesquisadores e pesquisadoras que consideram a educação como um espaço pertinente para esses debates, tendo em vista que nesse espaço circulam diferentes sujeitos, e consequentemente, diferentes valores que acabam imbricados com as formas de viver as identidades. Assim, torna-se indispensável pensar de que forma essas questões podem repercutir e interferir nos currículos.

Uma noção singular de gênero e sexualidade vem sustentando currículos e práticas de nossas escolas. Mesmo que se admita que existem muitas formas de viver os gêneros e a sexualidade, é consenso que a instituição escolar tem obrigação de nortear suas ações por um padrão: haveria apenas um modo adequado, legítimo, normal de masculinidade e de feminilidade e uma única forma sadia e normal de sexualidade, a heterossexualidade; afastar-se desse padrão significa buscar o desvio, sair do centro, tornar-se excêntrico (LOURO, 2010, p. 43).

Desta forma, a escola que sempre foi um espaço hostil ao "excêntrico", fazendo com que sujeitos LGBTQIA+ se distanciassem, a partir de um determinado momento, para evitar situações de violências, passa a ser alvo de investidas de educadores e educadoras para mudar esta realidade e tornar a instituição verdadeiramente para todos. César (2009) indica em suas reflexões que algumas pesquisas foram realizadas com professores, professoras e estudantes, comprovando a necessidade de formações na área da diversidade, pois gays, lésbicas, transexuais etc., também são seres humanos, e enquanto sujeitos compõem o universo escolar contemporâneo. César (2009) provocanos a pensar que:

${ }^{8}$ HIV é uma sigla para vírus da imunodeficiência humana. É o vírus que pode levar à síndrome da imunodeficiência adquirida (AIDS). Fonte: https://unaids.org.br/ 
[...] para esta instituição que nasceu disciplinar e normatizadora, a diferença, ou tudo aquilo que está fora da norma, em especial, a norma sexual, mostra ser insuportável por transbordar os limites do conhecido. Assim, um trabalho que assuma como princípio a diversidade sexual marca a entrada em um "campo epistemológico" desconhecido, na medida em que a "epistemologia" reconhecível é a do sistema heteronormativo de correspondência entre sexo-gênero (CÉSAR, 2009, p. 48).

No entanto, à medida que identificam este movimento, forças conservadoras em geral ligadas às religiões, passam a trabalhar no sentido contrário, deslegitimando professores, pesquisadores e chamando a educação sexual para o espaço privado, sob o argumento de que ela é dever das famílias. E mais, para gerar caos social, essas mesmas forças, que a cada dia que passa ocupam espaço maior também no legislativo brasileiro, afirmam em discursos inflamados nas tribunas e nas redes sociais, que os professores querem ensinar "pornografia" nas escolas e ensinar as crianças a "serem gays".

Por que devemos desconstruir esses discursos? Porque mesmo que saibamos que não se trata de ensinar pornografia - e nessa ordem discursiva é possível identificar a presença de um pré-conceito, pois vincula pornografia à sujeitos LGBTQIA+ - e mesmo que tenhamos a certeza de que sexualidade não se trata somente de sexo, extrapolando esse conceito para além do corpo humano, envolvendo questões comportamentais e de linguagens, imersas nos valores, representações e atitudes do ser (LOURO, 2007; MONTEIRO; RIBEIRO, 2020), ainda assim, repercutiram em revisões de legislações e documentos norteadores da educação, processos que acompanhamos desde os Planos Nacional ${ }^{9}$ e Municipais de Educação (PNE e PME), discutidos entre os anos de 2014 e 2015.

Souza Júnior (2018, p 13) afirma que houve supressões no texto do PNE, e segundo ele, motivadas "a pedido da bancada fundamentalista". Este aspecto pode ser acompanhado, também, em muitos municípios em que foi possível identificar grupos religiosos ocupando as plateias do legislativo no momento das votações, com cartazes contendo os dizeres "Respeito à família" e "Não à ideologia de gênero" conforme apresentamos na Figura 1.

Entendemos que esta ideia de "Respeito à família" sugere que a ótica dessas pessoas é a da família chamada nuclear, aquela composta por pai, mãe e filhos (FACO;

${ }^{9}$ O Plano Nacional de Educação determina diretrizes, metas e estratégias para a política educacional no período de 2014 a 2024. Fonte: http://pne.mec.gov.br/ 
MELCHIORI, 2009) e que qualquer outra configuração familiar que se distancie desse padrão, passa a ser uma configuração inferior, de menor valor, ou ainda, no caso de famílias com duas mães ou dois pais, algo considerado em suas perspectivas como “desviante", ou seja, uma afronta social.

FIGURA 1: Foto da votação do PME na cidade de Bagé/RS em 2015.

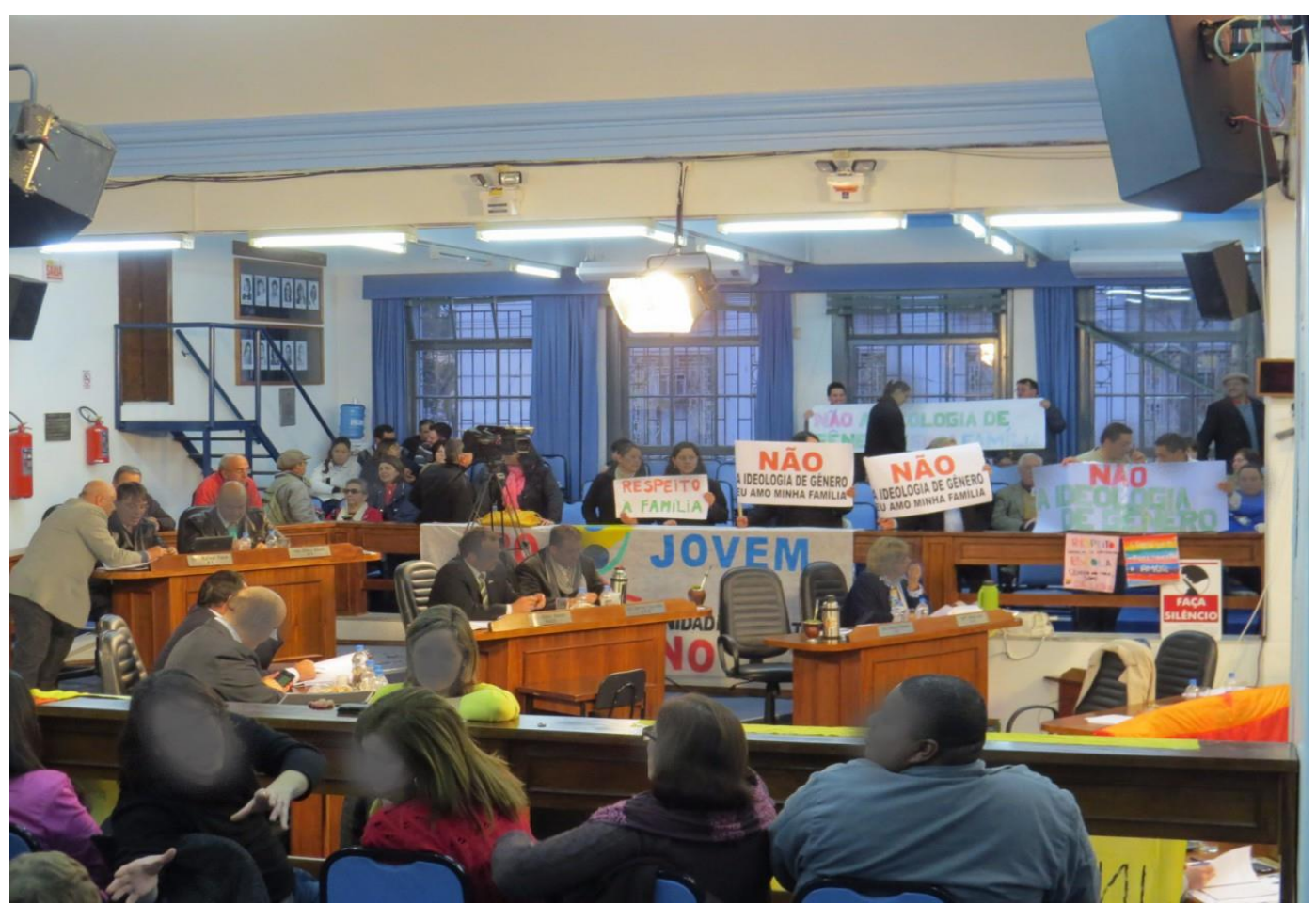

Fonte: Jornal Folha do Sul (2015)

Na ocasião desta votação, o Jornal Folha do Sul de 22 de julho de 2015, veiculou que o PME foi aprovado com a supressão do termo "preconceito", tendo sido essa supressão uma emenda de vereador ligado à uma igreja evangélica no município. Neste sentido, evidencia-se a influência desse viés religioso na vida das pessoas de um país que se pretendia laico.

De 1997 para cá, ocorreram muitas mudanças e desde a publicação dos Parâmetros Curriculares Nacionais houve significativa e importante ampliação do debate sobre Sexualidade e Educação Sexual; o movimento feminista e a discussão sobre Gênero e a igualdade da mulher tornaram-se presentes e ouvidos na sociedade brasileira; e o combate à homofobia e a defesa dos direitos LGBT passaram a fazer parte do discurso social e jurídico. No entanto, os ventos da repressão e da moralidade exacerbada e sem sentido começaram a chegar por volta de 2014 e, por ocasião da votação da "sucessora" dos PCN (embora fossem documentos totalmente 
distintos), uma onda de conservadorismo inundava o país (MONTEIRO; RIBEIRO, 2020, p. 4).

Ao considerar todos esses aspectos, é possível afirmar o quanto é importante dialogar sobre as temáticas envolvendo gênero e sexualidade na escola a fim de ressignificar algumas construções da nossa cultura que vêm sendo disseminadas ao longo dos anos, e o quanto elas se fazem presentes nos currículos escolares, dificultando a permanência de todos de forma saudável, tornando este ambiente avesso a algumas identidades e, por considerarmos que para uma escola e um currículo humanizado, eles devem contemplar essas múltiplas identidades, é que continuamos oferecendo resistência a esses grupos conservadores que têm atrapalhado a concepção de uma escola verdadeiramente inclusiva.

\section{Gênero, sexualidade e as concepções freireanas: a aproximação entre currículo e cultura}

Quando nos referimos a Paulo Freire e na sua relação com a educação, algumas frases e palavras vêm às nossas mentes quase que instantaneamente: prática da liberdade, dialogicidade e amorosidade. Para tanto, precisamos compreender e estimular a aplicação desses termos no campo educacional, não nos restringindo às meras reproduções sonoras e de grafia durante as discussões que permeiam os espaços escolares. Freire $(1967,2019)$ destaca que precisamos fazer das palavras um importante instrumento para a interpretação do mundo e transformação da realidade, a partir dos seus significados, não entendendo-as como ocas, em verbosidade alienada e alienante.

Nesta perspectiva freireana, a educação precisa assumir um caráter críticoemancipatório, ou seja, deve ser uma prática que liberta, uma prática dialógica e carregada de sentidos e intencionalidades. O objetivo dela deve ser a formação dos educandos e educandas em sua integralidade, garantindo a compreensão de seus direitos e deveres a partir do processo de tomada de consciência.

Quando os nossos direitos são negados, a cidadania não pode ser construída, e por consequência, não há preparo para que o cidadão exerça seu poder (SCOCUGLIA, 2005). Menezes e Santiago (2014) enfatizam que dentro de uma educação libertadora, o existir de homens e mulheres no mundo faz-se através do desenvolvimento da consciência, que permite a eles a apreensão crítica da realidade. As mesmas autoras destacam ainda que, ao estarem conscientes, homens e mulheres deixam a posição de 
oprimidos e passam a ser sujeitos de suas histórias, que são inacabadas, uma vez que a intercomunicação entre as subjetividades é um processo constante e constrói outros significados dentro de contextos históricos, sociais e culturais.

Portanto, a dialogicidade é considerada como um dos pilares da concepção freireana. As relações que se estabelecem entre sujeito-sujeito e sujeito-mundo, estimuladas pela problematização e criticidade, geram a todo instante novas criações, recriações, percepções e dinamizações, tendo origem no diálogo (FREIRE, 1967, 2019). Para Freire (1967, p. 107), este pode ser entendido como “[...] uma relação horizontal de A com B", e como toda relação, provoca algo entre os envolvidos. Segundo Dal-Cin, Rosa e Schwengber (2017), o diálogo:

comunica e promove uma relação entre os sujeitos provocando simpatia entre ambos. Há também em um diálogo amor, humildade, esperança, fé e confiança. E, por isso, o diálogo torna-se fundamental e indispensável como o caminho a ser trilhado nesta prática libertadora (DAL-CIN; ROSA; SCHWENGBER, 2017, p. 15536).

Como podemos perceber, a amorosidade está contida na dialogicidade. Freire (2019, p. 110) afirma que "não há diálogo, porém, se não há um profundo amor ao mundo e aos homens". Menezes e Santiago (2014, p. 53) destacam que "não se trata, segundo o autor, de um sentimento ingênuo ou romântico de afeição, ele se caracteriza por relações autênticas de respeito, tolerância e empatia entre pessoas que compartilham ideais na busca da humanização". Assim, a humanização é fruto da libertação, sustentada pelo diálogo e pelo amor. É na humanização que buscaremos evidenciar as conexões entre currículo e cultura em Freire.

Paulo Freire concebe em suas obras que os homens são singulares, são sujeitos históricos, que carregam consigo conhecimentos adquiridos em suas vivências e consequentemente produzem cultura. Logo, os educadores devem assumir o papel de mediadores, por meio da aproximação entre conhecimento cultural e conhecimento científico, possibilitando diante do confronto de informações, a problematização, a reflexão e a (re)construção de saberes que irão dar aos educandos e educandas a possibilidade de intervirem socialmente em suas realidades. Deste modo, Freire (1967) apresenta a cultura como um dos elementos de construção curricular, sendo importante para que os conteúdos façam sentido aos/às estudantes dentro de uma dimensão de totalidade, que enfatize além dos conceitos, as criações e manifestações sociais. 
Menezes e Santiago (2014) consideram que a humanização oferece um horizonte de possibilidades para a transformação social.

Na perspectiva de Mello, Rorato e Silva (2018), o currículo faz parte de um processo histórico, com intencionalidades, mas também se configura como uma construção social. Por isso, ao nos perguntarmos em que momento Freire viabiliza as discussões acerca das temáticas de Gênero e Sexualidade, devemos partir de suas concepções de currículo. Diante disso, é possível afirmar que Paulo Freire, ao considerar a participação da cultura produzida pelos sujeitos na formulação curricular, entende este como um instrumento que precisa refletir os valores e interesses de homens e mulheres, materializando-os nos espaços escolares. Isso inclui os conflitos conceituais de gênero e sexualidade manifestados nas relações escolares (FRANÇA; CALSA, 2011).

Pode-se afirmar também que a participação no processo educativo, de construção e reconstrução curricular, passa pelo diálogo. O currículo deve preocupar-se em fortalecer as relações estabelecidas pelos sujeitos a partir do tripé conhecimentoconsciência-diálogo, que reforça o elo entre as práxis social e educativa, bem como caminha ao encontro da coletividade que faz a educação e a escola (SCOCUGLIA, 2005). Na perspectiva de Saul (1998), uma relação dialética pode se instituir entre o currículo e o contexto histórico, social, político e cultural, assumindo-se enquanto projeto social que contribui com a emancipação dos sujeitos.

Portanto, os conteúdos não podem ser fragmentados e separados da dimensão de totalidade, devendo ser oportunizados junto aos/às estudantes e à comunidade de maneira sistematizada às problematizações que emergem diante de todas as vozes, que têm muito a dizer para além dos saberes disciplinares (MENEZES; SANTIAGO, 2014). Scocuglia (2005) ilustra esse movimento a partir de um exemplo:

[...] suponhamos que uma determinada escola esteja trabalhando o conteúdo corpo humano. Ora, todos os atores envolvidos têm experiência cotidiana, de vida, com esse objeto de conhecimento. Onde o processo educativo pretende chegar com esse conteúdo? A resposta óbvia é que se quer chegar num conhecimento cada vez mais elaborado (rigoroso, científico). Partindo de que, de onde? A resposta que se suporia lógica é pouco aplicada na prática: deveria partir do conhecimento do mundo, da "experiência feita", como diz Freire, para conquistar o conhecimento elaborado. Em outras palavras, o conhecimento do organismo humano, do seu funcionamento, dos seus sistemas etc, deveria ter como ponto inicial o conhecimento prático, do senso comum, que todos possuem sobre os mecanismos que fazem 
funcionar cada parte do nosso corpo, experimentado desde a mais tenra idade. Ademais, o conteúdo corpo humano, enquanto objeto de conhecimento das ciências físico-química-biológicas, não existe sem estar contextualizado (e problematizado) social, política, econômica e culturalmente. Sem estes contextos como poderíamos compreender, por exemplo, o fato de que os corpos humanos na região Nordeste do Brasil vivem aproximadamente 50 anos, em média, e no sul do país mais de 70 anos? (SCOCUGLIA, 2005, p. 82).

O exemplo proposto por Scocuglia (2005), nos dados mais atualizados do Instituto Brasileiro de Geografia e Estatística (IBGE) que foram publicados em 2019 e fazem referência ao ano de 2018, se evidencia que a expectativa de vida brasileira atualmente é de 76 anos e três meses, sendo que na região sul (Paraná, Santa Catarina e Rio Grande do Sul) o valor atinge a média de 78 anos e seis meses e na região nordeste (Alagoas, Bahia, Ceará, Maranhão, Paraíba, Pernambuco, Piauí, Rio Grande do Norte e Sergipe) 73 anos e quatro meses, conforme a Figura 2:

FIGURA 2: Gráfico do IBGE sobre a mortalidade brasileira em 2018.

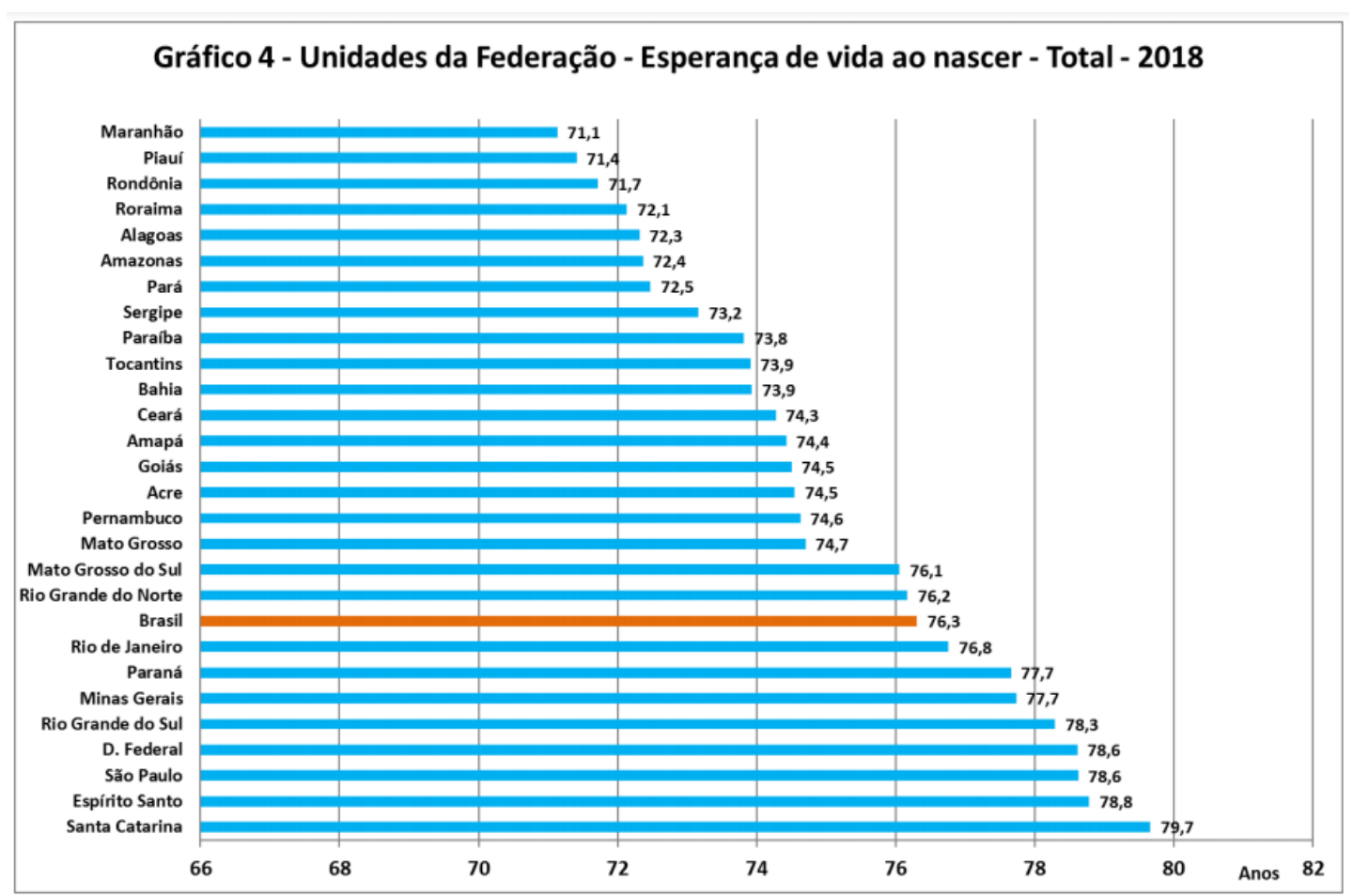

Fonte: Projeção da população do Brasil e Unidades da Federação por sexo e idade para o período 2010-2060.

Fonte: IBGE (2019)

O quadro acima evidencia que ainda há uma diferença entre a taxa de mortalidade dos estados nordestinos em comparação aos sulistas. Se voltarmos nossa atenção para os extremos, que não por coincidência, são caracterizados por um estado da região 
nordeste e um da região sul, a discrepância desses dados ainda é entendida por nós como assustadora. Mesmo que a diferença proposta por Scocuglia (2005) para o tempo de vida dos corpos fosse de 20 anos, de lá para cá já se passaram 15 anos, e essa desigualdade continua absurdamente alta, na casa dos oito anos e seis meses.

Dessa maneira, as demandas curriculares seguem exigindo diálogos que perpassam os conteúdos específicos de cada disciplina, uma vez que precisamos nos questionar, por exemplo: A que se deve a diminuição dessa diferença de tempo? Por qual motivo ela ainda ocorre? Quais são as condições da saúde pública (atendimentos médicos, saneamento básico, controle de doenças) de cada região? Essas condições só são possibilitadas quando a elaboração curricular contempla todos os sujeitos envolvidos no processo de aprender, recebendo subsídios para que se mantenham sensíveis no que se refere à percepção das múltiplas identidades, culturas e realidades, considerando-as sem exclusões. É esse currículo que fornecerá condições aos educandos e educandas para que interpretem esses e os demais dados, refletindo sobre possíveis ações que possam vir a contribuir com o cenário atual.

Em seu livro Pedagogia da Autonomia, Paulo Freire salienta que "ensinar exige risco, aceitação do novo e rejeição a qualquer forma de discriminação" (FREIRE, 2020, p. 36). Todavia, a discriminação surge há muitos anos, no decorrer da historicidade dos homens, logo, precisa compor também o currículo e ser discutida nos espaços educacionais para que possamos levantar questionamentos a fim de combatê-la. Na visão de Vasconcelos e Brito (2014, p. 79), a discriminação significa "uma ruptura com a decência, em qualquer instância que aconteça, pois o respeito pela cultura e pela identidade pessoal revela a coerência da prática educativa e do entender-se como ser humano ético, autônomo, democrático". Essas ideias aparecem também em Freire (2020):

A prática preconceituosa de raça, de classe, de gênero ofende a substantividade do ser humano e nega radicalmente a democracia. Quão longe dela nos achamos quando vivemos a impunidade dos que matam meninos nas ruas, dos que assassinam camponeses que lutam por seus direitos, dos que discriminam os negros, dos que inferiorizam as mulheres. Quão ausentes da democracia se acham os que queimam igrejas de negros porque, certamente, negros não têm alma. Negros não rezam. Com sua negritude, os negros sujam a branquitude das orações... A mim me dá pena e não raiva, quando vejo a arrogância com que a branquitude de sociedades em que se faz isso, em que se queimam igrejas de negros, se apresenta ao mundo como pedagoga da democracia. Pensar e fazer errado, pelo visto, não têm mesmo nada 
que ver com o bom-senso que regula nossos exageros e evita as nossas caminhadas até o ridículo e a insensatez. (FREIRE, 2020, p. 37).

A incorporação dessas temáticas na prática pedagógica do professor não é exagero, mas sim, uma necessidade. Para França e Calsa (2011), as culturas são compostas por conceitos e os indivíduos reproduzem seu comportamento a partir dos significados que circulam entre eles. As autoras evidenciam que "os discursos, dependendo de quem os emite, acabam por justificar e fornecer legitimidade às desigualdades de classe, gênero, etnia, raça, sexualidade" (FRANÇA; CALSA, 2011, p. 112).

De uma sociedade que se considera civilizada, esperava-se no mínimo que a violência e o preconceito não fizessem morada nos pensamentos e atitudes de algumas pessoas que constituem a sociedade brasileira. Não obstante, o que se constata em pleno século 21 são manifestações ideológicas, que apresentam em seu cerne os piores traços de intolerância. Negros são agredidos e/ou mortos diariamente em nível mundial ${ }^{10}$, a intolerância religiosa tem assolado o nosso país ${ }^{11}$ e como já dito nas palavras iniciais desse artigo, o Brasil é um dos países que mais agride e mata membros da comunidade LGBTQIA $+{ }^{12}$.

Em contrapartida, resgatamos mais uma vez o argumento de que no lugar da busca por soluções, temos hoje a BNCC aprovada e que carrega consigo várias intencionalidades, formatadas por interesses políticos, religiosos e mercadológicos, que ao invés de estimular o exercício da reflexão, opta por retirar termos, temas e temáticas que caminham em sentido oposto à ideologia hegemônica (MELLO; RORATO; SILVA, 2018; PICOLI, 2020). Trata-se de um documento que censura as singularidades, que desconsidera as especificidades de cada região brasileira ao impor de forma normatizadora um padrão único a ser seguido. Mantém o diagnóstico feito por França e Calsa (2011, p. 111), que defendem há algum tempo sua percepção de um ambiente escolar que é restrito "a um modelo de aluno que corresponde à norma social: um menino ou uma menina com as características de gênero, heterossexualidade e estrutura familiar compatíveis com o que é esperado pela sociedade".

${ }^{10}$ Caso João Pedro - São Gonçalo/RJ, 2020; Caso Guilherme Guedes - São Paulo/SP, 2020; Caso George Floyd - Minneapolis/EUA, 2020; Caso Jacob Blake - Kenosha/EUA, 2020.

${ }^{11}$ Caso de homem autônomo, 57 anos, que usando um Quipá levou chutes e socos - Jaguariúna/SP, 2020; Caso de idosa, 65 anos, agredida a pedradas por ser Candomblecista - Nova Iguaçu/RJ, 2017.

${ }^{12}$ Caso Dandara dos Santos, travesti torturada e morta por cinco homens - Fortaleza/CE, 2017; Caso Thadeu Nascimento, transexual morto a tiros - Salvador/BA, 2017; Caso Matheusa Passarelli, identidade de gênero não binária, que foi assassinada e possivelmente queimada - Rio de Janeiro/RJ, 2018. 
Por isso, defendemos um currículo humanizado, que sob o viés críticoemancipatório, deve ter suas concepções presentes na práxis do professor. É ele que associará fortemente o conhecimento científico aos conhecimentos, manifestações e criações culturais. Em outras palavras, considera e faz com que os sujeitos se insiram no debate sobre democracia, raça e crença. Além disso, faz com que problematizem gênero e sexualidade a partir dos diferentes conceitos elaborados a partir do contexto histórico, político, cultural e social (FRANÇA; CALSA, 2011).

Com isso, tendo na educação uma forma de intervenção no mundo (FREIRE, 2020), espera-se que uma vez liberto, conscientizado e crítico, o sujeito perceba as desigualdades de classes que se mostram sem hesitar, e dentro da práxis social, exerça seu papel enquanto ser democratizado, político e grande responsável pela transformação social, no "desmascaramento" das ideologias dominantes (FREIRE, 2020, p. 96).

\section{BNCC: o que encontramos e que reflexões fazemos?}

Ao sermos convidados à análise da BNCC, a fazemos a partir da nossa necessidade de vincularmos às questões que nos inquietam em nossa práxis docente, portanto, vamos abordar neste artigo mais especificamente sobre como a Base apresenta (ou não) as temáticas de gênero e sexualidade - o que para nós é de fundamental importância - se ela vai ao encontro de nossas compreensões e percepções acerca do currículo, e das relações que perpassam esse contexto educacional ou não.

Para tanto, iniciamos nossas reflexões registrando que a palavra gênero só foi encontrada no texto final da BNCC quando se refere a gênero textual/literário/musical. Abaixo é possível observar os dados gerados a partir da análise documental realizada no texto da BNCC (QUADRO 1). Para esta análise, em um primeiro momento, buscamos pelo descritor "gênero", que das 600 páginas do documento, aparece em 111 delas, distribuída entre Educação Infantil, Ensino Fundamental e Ensino Médio.

QUADRO 1: A palavra "Gênero" na BNCC.

\section{BNCC}

EDUCAÇÃO INFANTIL 


\begin{tabular}{|c|c|c|}
\hline & Como aparece & Páginas \\
\hline Os campos das experiências & Gêneros literários & 42 \\
\hline Objetivos de aprendizagem & Gêneros textuais & 50 \\
\hline Transição para o Ensino Fund. & Gêneros textuais & 55 \\
\hline \multirow{2}{*}{ ÁREAS } & \multicolumn{2}{|c|}{ ENSINO FUNDAMENTAL } \\
\hline & Como aparece & Páginas \\
\hline Linguagens & $\begin{array}{l}\text { Gênero textual, literário, } \\
\text { musical, escrito, digital... }\end{array}$ & $\begin{array}{l}67,68,69,72,73, \\
74,75,77,78,79, \\
80,83,84,85,87, \\
89,93,95,96,102, \\
103,104,105,107, \\
108,109,110,111, \\
112,113,118,119, \\
121,122,123,125, \\
127,128,131,132, \\
133,136,137,138, \\
139,140,141,143, \\
145,146,147,149, \\
150,151,153,154, \\
155,156,157,159, \\
160,161,162,163, \\
164,165,166,167, \\
169,171,175,176, \\
177,179,181,182, \\
183,187,191,203, \\
209,243,244,263\end{array}$ \\
\hline Ciências Humanas & Gêneros textuais & 357 \\
\hline \multirow[b]{2}{*}{ ÁREAS } & \multicolumn{2}{|c|}{ ENSINO MÉDIO } \\
\hline & Como aparece & Páginas \\
\hline Linguagens e suas tecnologias & $\begin{array}{c}\text { Gêneros textuais, artístico, do } \\
\text { discurso... }\end{array}$ & $\begin{array}{l}487,494,498,499, \\
502,503,504,506, \\
507,509,510,511, \\
512,515,516,517, \\
518,519,522,524, \\
525,526\end{array}$ \\
\hline Ciências da Natureza & Gêneros textuais & 551 \\
\hline
\end{tabular}

Fonte: Autores

O quadro acima se divide em três colunas, sendo uma voltada às áreas do conhecimento em que encontramos a palavra gênero, seguido por outras duas colunas que informam de que maneira o gênero aparece e em quais páginas do documento, respectivamente. Da mesma forma, ao observarmos a divisão horizontal das informações, identificaremos também três momentos: Educação Infantil, Ensino 
Fundamental e Ensino Médio. Como percebemos, a etapa em que a palavra gênero menos aparece é a da Educação Infantil, fazendo-se mais presente na área das Linguagens referente ao Ensino Fundamental, mais especificamente na Língua Portuguesa, nas Artes e na Língua Inglesa, e posteriormente no Ensino Médio, nas Linguagens e suas Tecnologias.

Encontramos ainda algumas aparições na área de Ciências Humanas no Ensino Fundamental e na de Ciências da Natureza, do Ensino Médio, ambas se referindo aos gêneros textuais e não à ideia de gênero enquanto construção social em torno dos atributos femininos e masculinos, conforme identificamos na área dos estudos de gênero, o que nos fez pensar que na Base não há espaço para essa discussão. Monteiro e Ribeiro (2020) afirmam que a palavra gênero e a expressão orientação sexual foram suprimidas da versão final da BNCC e vinculam tal afirmação aos movimentos de grupos políticos conservadores, ligados a instituições religiosas.

$\mathrm{O}$ trecho que defendia o respeito à orientação sexual de cada um foi suprimido, um dos exemplos de que a elaboração e aprovação da Base Nacional Comum Curricular passaram pelo crivo cultural mencionado, ficando à mercê de influências religiosas fundamentalistas, conservadoras e moralizantes que, em detrimento da ciência, eliminaram de seu texto final todo conteúdo associado a Gênero... (MONTEIRO; RIBEIRO, 2020, p. 11).

A mesma análise realizada para o gênero na BNCC foi realizada para a sexualidade, na qual quisemos identificar quantas vezes ela era abordada no documento. Para nossa surpresa, aparece apenas três vezes ao longo das 600 páginas da BNCC, conforme vemos no quadro abaixo.

QUADRO 2: A sexualidade na BNCC.

\section{BNCC}

ENSINO FUNDAMENTAL 


\begin{tabular}{|c|c|c|}
\hline ÁREA & Como aparece & Páginas \\
\hline Ciências- $8^{\text {o }}$ ano & $\begin{array}{c}\text { Vinculada à reprodução, } \\
\text { enfatizando a dimensão } \\
\text { biológica }\end{array}$ & $327,348,349$ \\
\hline
\end{tabular}

Fonte: Autores

Semelhante ao que fizemos para o descritor gênero, procuramos buscar agora o descritor "sexualidade". No quadro acima, é possível identificar as três colunas, em que descrevemos a área das Ciências do $8^{\circ}$ ano do Ensino Fundamental, onde o descritor foi encontrado, bem como a forma como aparece e em quais páginas. Examinando estas páginas, podemos perceber que a abordagem da sexualidade centra-se na dimensão biológica, pois o documento a conecta com a área de ciências, enfatizando o estudo e conhecimento da reprodução e da importância dos cuidados com o corpo e prevenção de doenças, ou seja, "reduziram à ótica biológica os assuntos ligados à Sexualidade" (MONTEIRO; RIBEIRO, 2020, p. 12). Reis e Goularth (2017) concordam com esse argumento e reconhecem essas questões como político e socialmente importantes para a educação, uma vez que fazem parte da sociedade. Os autores entendem sobre o gênero que:

\begin{abstract}
Além de estar dentro de uma discussão e legitimação científica, enquanto área de estudo, o estudo de gênero na Educação Básica ainda é alvo de tabu, restringindo-se muitas vezes às abordagens no Ensino de Biologia, no qual o enfoque são as desigualdades biológicas entre homens e mulheres, abordadas superficialmente e voltadas para a reprodução humana (REIS; GOULARTH, 2017, p. 90).
\end{abstract}

Percebe-se com essa busca que a Base descaracteriza as orientações dadas anteriormente, em outros documentos oficiais, que tratavam de assumir as temáticas de gênero e sexualidade como os temas transversais que deviam ser trabalhados em todas as disciplinas da Educação Básica, como os PCN e as OCEM. Traremos alguns exemplos encontrados a partir da leitura das OCEM (BRASIL, 2006a, 2006b), voltando nossa análise para os volumes que não retratam a dimensão das Ciências Biológicas. A sistematização que se encontra no Quadro 3 foi construída a partir da busca nos volumes um e três, pelos termos "gênero", "sexualidade" e "sexual":

QUADRO 3: Presença das temáticas de gênero e sexualidade nas OCEM.

\begin{tabular}{|c|c|c|c|}
\hline Volume & Gênero & Sexualidade & Página (s) \\
\hline & Mostra-se & Mostra-se valorizada dentro & \\
\hline
\end{tabular}




\begin{tabular}{|c|c|c|c|}
\hline $\begin{array}{c}1- \\
\text { Linguagens, } \\
\text { códigos e } \\
\text { suas } \\
\text { Tecnologias }\end{array}$ & 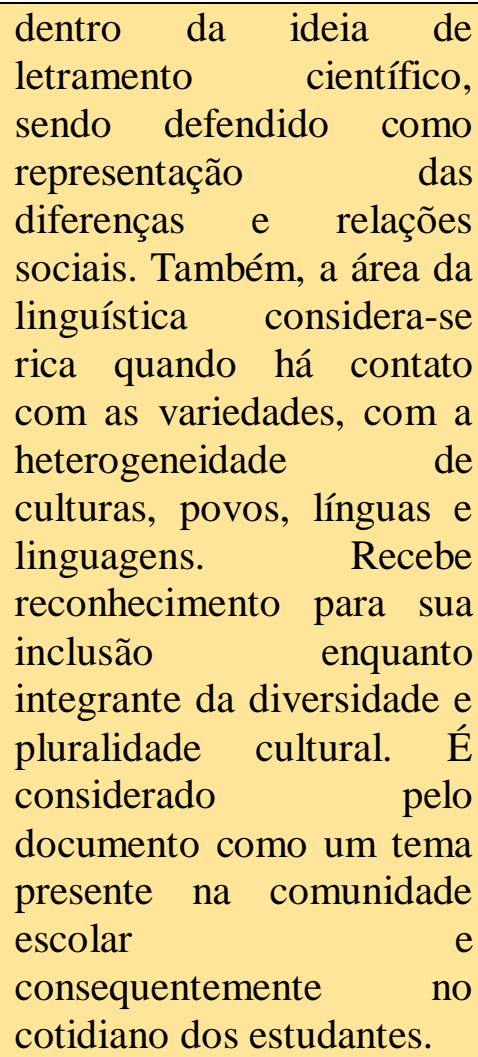 & $\begin{array}{l}\text { da ideia de letramento } \\
\text { científico, sendo defendida } \\
\text { como representação das } \\
\text { diferenças e relações } \\
\text { sociais. } \\
\text { reconhecimento para sua } \\
\text { inclusão enquanto integrante } \\
\text { da diversidade e pluralidade } \\
\text { cultural. É considerada pelo } \\
\text { documento como um tema } \\
\text { presente na comunidade } \\
\text { escolar e consequentemente } \\
\text { no cotidiano dos estudantes. }\end{array}$ & $\begin{array}{l}20,116, \\
137,177, \\
186,203, \\
215,220, \\
228,229 .\end{array}$ \\
\hline $\begin{array}{l}3 \text { - Ciências } \\
\text { Humanas e } \\
\text { suas } \\
\text { Tecnologias }\end{array}$ & $\begin{array}{l}\text { Reconhecido como parte } \\
\text { de um sujeito histórico, } \\
\text { caracterizado } \\
\text { transformações por } \\
\text { ocorrem através das } \\
\text { interações do homem com } \\
\text { ele mesmo ou com a } \\
\text { natureza e que fazem parte } \\
\text { da formação social e } \\
\text { cultural da humanidade e } \\
\text { sua diversidade. Encontra- } \\
\text { se vinculado ao conceito } \\
\text { de cidadania. É visto como } \\
\text { potencialidade de tema a } \\
\text { ser trabalhado com os } \\
\text { estudantes. }\end{array}$ & $\begin{array}{l}\text { Encontra-se vinculado ao } \\
\text { conceito de cidadania. É } \\
\text { reconhecida como um } \\
\text { elemento da cultura } \\
\text { humana. É vista como um } \\
\text { tema da diversidade com } \\
\text { potencial a ser desenvolvido } \\
\text { em projetos que } \\
\text { contemplem políticas } \\
\text { afirmativas e de inclusão } \\
\text { social. Também é vista } \\
\text { como potencialidade de } \\
\text { tema a ser trabalhado com } \\
\text { os estudantes. }\end{array}$ & $\begin{array}{c}25,75,76, \\
77,83,93, \\
120,121 .\end{array}$ \\
\hline
\end{tabular}

Fonte: Autores

Como visto no Quadro 3, que encontra-se dividido em quatro colunas, a primeira indica o volume das OCEM que foi analisado, a segunda tem relação com o termo gênero contido no documento, a terceira tem relação com o termo sexualidade contido no documento, e por fim, a quarta coluna retrata as páginas em que os dois termos foram encontrados. É possível perceber que as OCEM destacam o reconhecimento da integralidade dos sujeitos, respeitando suas singularidades, as diferentes culturas e apresentam propostas para a prática pedagógica dentro das escolas. Em detrimento 
disso, a BNCC encontra-se dividida em competências e habilidades e, para demonstrarmos o viés biologicista de que trata o texto da Base, quando aborda as questões relacionadas à sexualidade, apresentamos abaixo um quadro contendo a subdivisão em "Unidade Temática”, “Objetos do Conhecimento" e "Habilidades" para o ensino de ciências aos/às estudantes do $8^{\circ}$ ano do ensino fundamental, conforme as páginas 348 e 349 do documento.

QUADRO 4: A sexualidade no ensino de ciências do $8^{\circ}$ ano do ensino fundamental na BNCC.

\begin{tabular}{|c|c|c|}
\hline $\begin{array}{l}\text { Unidade } \\
\text { Temática }\end{array}$ & $\begin{array}{c}\text { Objetos do } \\
\text { Conhecimento }\end{array}$ & Habilidades \\
\hline $\begin{array}{c}\text { Vida e } \\
\text { evolução }\end{array}$ & $\begin{array}{l}\text { Mecanismos } \\
\text { reprodutivos } \\
\text { Sexualidade }\end{array}$ & $\begin{array}{l}\text { (EF08CI07) Comparar diferentes processos } \\
\text { reprodutivos em plantas e animais em relação } \\
\text { aos } \\
\text { mecanismos adaptativos e evolutivos. } \\
\text { (EF08CI08) Analisar e explicar as } \\
\text { transformações que ocorrem na puberdade } \\
\text { considerando a } \\
\text { atuação dos hormônios sexuais e do sistema } \\
\text { nervoso. } \\
\text { (EF08CI09) Comparar o modo de ação e a } \\
\text { eficácia dos diversos métodos contraceptivos } \\
\text { e justificar a necessidade de compartilhar a } \\
\text { responsabilidade na escolha e na utilização } \\
\text { do método mais adequado à prevenção da } \\
\text { gravidez precoce e indesejada e de Doenças } \\
\text { Sexualmente Transmissíveis (DST). } \\
\text { (EF08CI10) Identificar os principais sintomas, } \\
\text { modos de transmissão e tratamento de algumas } \\
\text { DST (com ênfase na AIDS), e discutir } \\
\text { estratégias e métodos de prevenção. } \\
\text { (EF08CI11) Selecionar argumentos que } \\
\text { evidenciem as múltiplas dimensões da } \\
\text { sexualidade a } \\
\text { humana (biológica, sociocultural, afetiva e } \\
\text { ética). }\end{array}$ \\
\hline
\end{tabular}

Fonte: BRASIL (2018, p. 348-349)

Ao analisarmos as habilidades que se pretende desenvolver com esses sujeitos, identificamos que, embora a última habilidade mencione "múltiplas dimensões da sexualidade humana (biológica, sociocultural, afetiva e ética)", enfatiza anteriormente os aspectos funcionais do corpo como atuação dos hormônios, métodos contraceptivos e 
de prevenção a doenças. Não queremos com isso anular a importância desses processos para a saúde e bem-estar de nossas crianças e jovens, mas sinalizamos aqui com nossa crítica que, não nos parece haver espaço para de fato desenvolver as dimensões socioculturais, afetivas e éticas da sexualidade, pois não faz referência objetiva às múltiplas identidades, não abordando as identidades de gênero e sexuais. Sendo assim, como seria possível tratar das dimensões afetivas e éticas se as diferentes expressões e vivências da sexualidade não forem consideradas e debatidas? Este aspecto também é observado por Silva, Brancaleoni e Oliveira (2019, p. 1547):

a décima primeira habilidade apresenta fragilidades que poderão levar ao seu não desenvolvimento ou desenvolvimento falho pelos estudantes. Ao considerarmos o contexto de habilidades que a antecede, verificamos que o documento oficial não subsidia $o$ professor a planejar sua atuação de modo a contemplar as múltiplas dimensões da sexualidade dado que a BNCC enfatiza apenas aspectos biológicos em detrimento de outras dimensões que atravessam a sexualidade humana.

Além disso, a própria tensão gerada por meio dessas discussões sobre retirar ou não a temática dos conteúdos escolares pode gerar por si só o receio por parte dos professores e professoras em oportunizar esses debates na sala de aula, fortalecendo o imaginário social de que a sexualidade é assunto para a esfera privada. Ainda neste processo de estudo da Base, em nossa análise documental identificamos algumas contradições, conforme podemos verificar a partir das reflexões sobre o trecho que segue em relação às Ciências Humanas.

As Ciências Humanas devem, assim, estimular uma formação ética, elemento fundamental para a formação das novas gerações, auxiliando os alunos a construir um sentido de responsabilidade para valorizar: os direitos humanos; o respeito ao ambiente e à própria coletividade; o fortalecimento de valores sociais, tais como a solidariedade, a participação e o protagonismo voltados para o bem comum; e, sobretudo, a preocupação com as desigualdades sociais (BRASIL, 2018, p. 354).

Nos parece contraditório porque um documento que pretende estimular a formação ética de forma que os/as estudantes passem a valorizar os direitos humanos, sob uma suposta preocupação com as desigualdades sociais, suprime gênero e orientação sexual do debate na escola, se coloca contra qualquer possibilidade de ser efetivamente ético e plural, pois não proporciona que os sujeitos reflitam ao ponto de 
tomar consciência sobre as desigualdades de gênero, refletir sobre as violências e o impacto social que exercem na vida em sociedade.

Ainda nas Ciências Humanas, que trazem como a primeira competência "Compreender a si e ao outro como identidades diferentes, de forma a exercitar o respeito à diferença em uma sociedade plural e promover os direitos humanos" (BRASIL, 2018, p. 357), apresentamos o seguinte questionamento: mas de que identidades trata o documento? Se a Base não aborda as diferentes identidades de gênero e sexual, como ela pode pretender que a formação dos sujeitos seja "orientada por valores democráticos" (BRASIL, 2018, p. 354).

Agora no que se refere ao Ensino Religioso, a BNCC traz a competência "Conviver com a diversidade de crenças, pensamentos, convicções, modos de ser e viver" (BRASIL, 2018, p. 437). No entanto, ao desconsiderar os modos de ser dos diferentes sujeitos e de viver as sexualidades, novamente nos deparamos com movimentos contraditórios.

Com base no exposto, de posse da certeza de que a BNCC necessitaria ainda de muitas reflexões, pois foi um documento teoricamente elaborado a partir de uma construção coletiva, constituída de pessoas de diferentes subjetividades, e mais que isso, uma construção influenciada por vieses religiosos e conservadores, caminhamos agora para as nossas considerações finais.

\section{Conclusão}

A partir dessa análise é possível afirmar que o documento oficial da Base consolida legalmente uma prática bastante comum dentre algumas instituições educacionais que mantêm práticas de ensino mais tradicionais, como Reis e Goularth (2017) apontam que apesar da presença das temáticas ser necessária em sala de aula, alguns indivíduos ou o próprio currículo das instituições de ensino inviabilizam tais debates e ocultam a diversidade, fortalecendo ideias conservadoras de gênero e que consideram apenas os aspectos biológicos da sexualidade humana.

Assim, é possível identificar identidades negadas no texto da Base, pois não há espaço para que todos os sujeitos sejam contemplados e possam de fato fazer parte e construírem suas histórias. Se isso não acontece, não dispomos de um currículo humanizado, conforme a perspectiva freireana, com espaços para o diálogo, onde todas as vozes tenham vez. Neste caso, deparamo-nos com um documento de caráter 
normativo, que não é currículo, mas que possui várias intencionalidades para a prescrição curricular a partir do que se entende por conjunto de aprendizagens que os/as estudantes têm direito a aprender e aferição do que deve ser ensinado (MELLO; RORATO; SILVA, 2018; PICOLI, 2020).

Dessa forma, voltando-se à BNCC sob uma perspectiva analítica, é possível afirmar que ela retrocede em relação a documentos oficiais que antecedem sua aprovação, por exemplo os PCN e as OCEM, que traziam a possibilidade desses debates como temas transversais. À medida em que não é possível dialogar sobre a diversidade identitária, tal como ela se apresenta na sociedade, nos distanciamos de uma educação crítico-emancipatória dos sujeitos.

Sem refletir sobre estes aspectos, permitimos que a educação brasileira se desenvolva a mercê de grupos conservadores e de preceitos religiosos que excluem e marginalizam sujeitos, e que da mesma forma, desvalorizam a educação e os professores na medida em que regulam o que estes podem e não podem ensinar, como se não soubessem exercer o exercício docente com ética e responsabilidade.

\section{Referências}

BRASIL. Ministério de Educação. Secretaria de Educação Básica. Orientações Curriculares para o Ensino Médio: Ciências Humanas e suas Tecnologias. Brasília, DF. v. 3, 2006a. 133 p. Disponível em: http://portal.mec.gov.br/seb/arquivos/pdf/book_volume_03_internet.pdf. Acesso em: 13 set. 2020.

. Ministério de Educação. Secretaria de Educação Básica. Orientações

Curriculares para o Ensino Médio: Linguagens, Códigos e suas Tecnologias. Brasília, DF. v. 1, 2006b. 239 p. Disponível em:

http://portal.mec.gov.br/seb/arquivos/pdf/book_volume_01_internet.pdf. Acesso em: 13 set. 2020.

Ministério de Educação. Secretaria de Educação Fundamental. Base Nacional Comum Curricular. Brasília, DF. 2018. Disponível em:

http://basenacionalcomum.mec.gov.br/images/BNCC_EI_EF_110518_versaofinal_site. pdf. Acesso em 16 ago. 2020.

CELLARD, André. A análise documental. In: POUPART, Jean; DESLAURIERS, Jean-Pierre; GROULX, Lionel-H; LAPERRIÈRE, Anne; MAYER, Robert; PIRES, Álvaro. A pesquisa qualitativa: enfoques epistemológicos e metodológicos. 3 ed. Petrópolis, RJ: Vozes, 2012. p. 295-316. 
CÉSAR, Maria Rita de Assis. Gênero, sexualidade e educação: notas para uma "Epistemologia". Educar, Curitiba, n. 35. 2009. Disponível em:

https://www.scielo.br/pdf/er/n35/n35a04.pdf. Acesso em: 14 set. 2020.

DAL-CIN. Daniela; ROSA. Luciane da; SCHWENGBER. Ivan Luís. Um Currículo Freireano: Reflexões a partir da obra "Educação como prática de liberdade". In. XIII CONGRESSO NACIONAL DE EDUCAÇÃO (EDUCERE), 13., 2017. Anais... Paraná: Programa de Pós-Graduação em Educação Stricto Sensu, Curso de Pedagogia e Centro Acadêmico Paulo Freire da Pontifícia Universidade Católica do Paraná (PUCPR) e Centro Internacional de Estudos em Representações Sociais e Subjetividade - Educação (CIERS-ed) da Fundação Carlos Chagas (FCC), 2017. p. 15534 - 15547. Disponível em: https://educere.bruc.com.br/arquivo/pdf2017/24859_13133.pdf. Acesso em: 11 set. 2020.

FACO, Vanessa Marques Gibran; MELCHIORI, Lígia Ebner. Conceitos de família: adolescentes de zonas rural e urbana. In: VALLE, Tânia Gracy Martins do (Org.). Aprendizagem e desenvolvimento humano: avaliações e intervenções [online]. São Paulo: Cultura Acadêmica, 2009. p. 121-135. Disponível em:

http://books.scielo.org/id/krj5p/pdf/valle-9788598605999-07.pdf. Acesso em 15 set. 2020.

FRANÇA, Fabiane Freire; CALSA, Geiva Carolina. Gênero e sexualidade na formação docente: desafios e possibilidades. Sociais e Humanas, Santa Maria, v. 24, n. 02, jul./dez. 2011. Disponível em:

https://periodicos.ufsm.br/sociaisehumanas/article/view/2828/2858. Acesso em: 12 set. 2020.

FREIRE, Paulo. Educação como prática da liberdade. 1. ed. Rio de Janeiro: Paz e Terra, 1967. $192 \mathrm{p}$.

Pedagogia da autonomia: saberes necessários à prática educativa. 63 . ed. Rio de Janeiro/São Paulo: Paz e Terra, 2020. 143 p.

Pedagogia do oprimido. 71. ed. Rio de Janeiro/São Paulo: Paz e Terra, 2019. 256 p.

FUNDAÇÃO INSTITUTO BRASILEIRO DE GEOGRAFIA E ESTATÍSTICA, 2019. IBGE População: Tábuas completas de mortalidade. Tábua completa de mortalidade para o Brasil - 2018. Disponível em:

https://biblioteca.ibge.gov.br/visualizacao/periodicos/3097/tcmb_2018.pdf. Acesso em: 11 nov. 2019.

GALIAN, Cláudia Valentina Assumpção. Os PCN e a elaboração de propostas curriculares no Brasil. Cadernos de Pesquisa, São Paulo, v. 44, n. 153, jul./set. 2014. Disponível em: https://www.scielo.br/scielo.php?script=sci_arttext\&pid=S0100$15742014000300009 \& \operatorname{lng}=$ pt\&tlng=pt. Acesso em: 15 set. 2020.

KRIPKA, Rosana Maria Luvezute; SCHELLER, Morgana; BONOTTO, Danusa de Lara. Pesquisa Documental: considerações sobre conceitos e características na Pesquisa Qualitativa. In: CONGRESSO IBERO-AMERICANO EM INVESTIGAÇÃO 
QUALITATIVA, 4., 2015. Anais... Sergipe: Universidade Tiradentes, 2015. p. 243247.

LOURO, Guacira Lopes. Gênero, Sexualidade e educação: das afinidades políticas às tensões teórico-metodológicas. Educação em Revista, Belo Horizonte, n. 46. 2007. Disponível em: <https://www.scielo.br/pdf/edur/n46/a08n46.pdf>. Acesso em: 13 set. 2020.

Currículo, gênero e sexualidade: o "normal", o "diferente" e o "excêntrico". In: LOURO, Guacira Lopes; FELIPE, Jane; GOELLNER, Silvana Vilodre (Org.). Corpo, Gênero e Sexualidade: um debate contemporâneo na educação. $6^{a}$ ed. Petrópolis, RJ: Vozes, 2010. p. 41-52.

MELLO, Elena Maria Billig; RORATO, Adriana; SILVA, Luciane Grecilo da. BNCC pra que(m)? disfarces e contradições num processo marcado por muitas (in)definições. In: XII REUNIÃO CIENTÍFICA REGIONAL SUL DA ASSOCIAÇÃO NACIONAL DE PESQUISA E PÓS-GRADUAÇÃO EM EDUCAÇÃO (ANPEDSUL), 12., 2018. Anais... Rio Grande do Sul: Associação Nacional de Pesquisa e PósGraduação em Educação, 2018. Disponível em: http://anais.anped.org.br/regionais/sites/default/files/trabalhos/2/1609TEXTO_PROPOSTA_COMPLETO.pdf. Acesso em: 16 ago. 2020.

MENEZES, Marilia Gabriela de; SANTIAGO, Maria Eliete. Contribuição do pensamento de Paulo Freire para o paradigma curricular crítico-emancipatório. Pro-Posições, Campinas, v. 25, n. 3, set./dez. 2014. Disponível em: https://www.scielo.br/pdf/pp/v25n3/v25n3a03.pdf. Acesso em: 09 set. 2020.

MONTEIRO, Solange Aparecida de Souza. RIBEIRO, Paulo Rennes Marçal.

Sexualidade e Gênero na atual BNCC: possibilidades e limites. Pesquisa e Ensino, Barreiras, v. 1, e202011. 2020. Disponível em:

https://revistas.ufob.edu.br/index.php/pqe/article/view/626. Acesso em: 16 ago. 2020.

PICOLI, Bruno Antonio. Base Nacional Comum Curricular e o canto da sereia da educação normalizante: a articulação neoliberal-neoconservadora e o dever éticoestético da resistência. Revista de Estudios Teóricos y Epistemológicos en Política Educativa, v. 5, e2015036. 2020. Disponível em:

https://revistas2.uepg.br//index.php/retepe/article/view/15036. Acesso em 14 set. 2020.

PIMENTEL, Alessandra. O método da análise documental: seu uso numa pesquisa historiográfica. Cadernos de Pesquisa, n. 114, nov. 2001. Disponível em: https://www.scielo.br/pdf/cp/n114/a08n114.pdf. Acesso em 15 set. 2020.

PRÁ, Jussara Reis; CEGATTI, Amanda Carolina. Gênero, educação das mulheres e feminização do magistério no ensino básico. Revista Retratos da Escola, Brasília, v. 10, n. 18, jan./jun. 2016. Disponível em:

http://retratosdaescola.emnuvens.com.br/rde/article/viewFile/660/682. Acesso em: 02 ago. 2020.

REIS, Neilton dos; GOULARTH, Isabela dos Reis. Questões de Gênero no Ensino Médio: interfaces em Sociologia, Biologia e Interdisciplinaridade. Revista Café com 
Sociologia, v. 6, n. 1, jan./abr. 2017. Disponível em:

https://revistacafecomsociologia.com/revista/index.php/revista/article/view/774/pdf.

Acesso em: 13 set. 2020.

RIBAS, Jéssica Erd; SANTOS, Guilherme Pinto dos; STURZA, Raquel Brum.

Formação integral, interdisciplinaridade e contextualização no currículo do ensino médio brasileiro: que conceitos são esses? In: IV CONGRESO

LATINOAMERICANO DE FILOSOFÍA DE LA EDUCACIÓN. MEMORIA Y

PROSPECTIVA, LOS DESAFÍOS EN LA REGIÓN, 4., 2017. Anais... Buenos Aires:

Universidad Nacional de San Martín, 2017. Disponível em:

http://filosofiaeducacion.org/actas/index.php/act/article/view/299/280. Acesso em: 16 set. 2020.

SAUL, Ana Maria. A construção do currículo na teoria e prática de Paulo Freire. In: APPLE, Michael; NÓVOA, António. (Org.). Paulo Freire: política e pedagogia. Porto: Porto Editora, 1998. 192 p.

SCOCUGLIA, Afonso Celso. As reflexões curriculares de Paulo Freire. Revista Lusófona de Educação, Lisboa, n. 6. 2005. Disponível em:

http://www.scielo.mec.pt/pdf/rle/n6/n6a07.pdf. Acesso em: 10 set. 2020.

SILVA, Caio Samuel Franciscati; BRANCALEONI, Ana Paula Leivar; OLIVEIRA, Rosemary Rodrigues de. Base Nacional Comum Curricular e diversidade sexual e de gênero: (des) caracterizações. Revista Ibero-americana de Estudos em Educação. Araraquara. v. 14, n. esp. 2. jul/2019. Disponível em: https://periodicos.fclar.unesp.br/iberoamericana/article/view/12051. Acesso em 15 set. 2020.

SOUZA JÚNIOR, Paulo Roberto. A Questão de Gênero, Sexualidade e Orientação Sexual na atual Base Nacional Comum Curricular (BNCC) e o Movimento LGBTTQIS. Revista de Gênero, Sexualidade e Direito. v. 4, n. 1, jan/jun. 2018. Disponível em: <https://www.indexlaw.org/index.php/revistagsd/article/view/3924/pdf>. Acesso em 08 set. 2020.

VASCONCELOS, Maria Lúcia Marcondes Carvalho; BRITO, Regina Helena Pires de. Conceitos de educação em Paulo Freire. 6. ed. Petrópolis: Editora Vozes Ltda, 2014. $200 \mathrm{p}$. 